\title{
ORDENANZAS MUNICIPALES DE OURENSE EN EL SIGLO XV: ESTUDIO INTRODUCTORIO*
}

\author{
ASCENSIÓN ENJO BABÍO \\ (Archivo Histórico Provincial de Ourense) \\ M. ${ }^{a}$ GLORIA DE ANTONIO RUBIO \\ (CSIC-Xunta de Galicia)
}

\begin{abstract}
Resumen
La ordenanzas municipales medievales reflejan la preocupación del concejo por los problemas cotidianos y las decisiones adoptadas para resolverlos. En Ourense, se conservan un grupo de ordenanzas correspondientes al siglo $\mathrm{XV}$ que muestran las decisiones adoptadas por el concejo en materia de policía urbana y rural, salubridad, abastecimiento, exequias, etc., y que permiten un estudio detallado acerca de su estructura y procedimiento de elaboración.
\end{abstract}

\section{Palabras clave}

\begin{abstract}
Abstrac
The medieval municipal ordinances reflect the worry of the council by the daily problems and the decisions adopted to resolve them. In Ourense, a group of ordinances corresponding to the fifteenth century are preserved and they show the decisions adopted by the council in matter of urban and rural police, salubriousness, provision, funeral rites, etc. They permit also a detailed study about their structure and their elaboration procedure.
\end{abstract}

\section{Key Words}

Galicia, Ourense, Middel Age, Medieval municipal ordinances 
Antes de iniciar el estudio de las ordenanzas de Ourense es necesario señalar que la palabra «Ordenanza» no ha tenido el mismo significado a lo largo de la historia. En la Edad Media y Moderna se entendió por ordenanza tanto las órdenes emanadas del rey para la organización administrativa del Estado, como para las villas y ciudades. Por este motivo, las ordenanzas se referían tanto a las normas dadas por el rey, como por un concejo. Otra acepción tradicional era atribuir a la palabra ordenanza una connotación predominantemente castrense. Uniendo ambos significados, local y militar, las ordenanzas se definían como «ley o estatuto que se manda observar y, especialmente, se da este nombre a las que están hechas para el régimen de los militares y buen gobierno de las tropas, o para el de alguna ciudad o comunidad»1.

En la actualidad, las ordenanzas son definidas como «Textos jurídicos que desde la Baja Edad Media a nuestros días recogen la regulación de la vida local en materias propias de la competencia de sus instituciones y autoridades» ${ }^{2} \mathrm{o}$ como «toda norma general, cualquiera sea su autor, cuyo ámbito territorial se circunscribe al municipio que se dicta para él y que regula aspectos de la vida económica, social, vecinal de organización y funcionamiento del concejo, su actividad y competencia» ${ }^{3}$.

Por lo tanto, siguiendo estas últimas definiciones se entenderá a lo largo de este artículo por ordenanza la serie de órdenes encaminadas a regular la convivencia de una comunidad y que son fruto de las necesidades reales de los concejos.

Las ordenanzas surgen en un momento en que los fueros, expresión de la autonomía municipal, estaban en un proceso de degradación normativa. A partir de este momento serán ellas las encargadas de desarrollar y regular materias de la vida social y municipal, además de ocuparse de la organización administrativa, de la policía, de la sanidad y de la vida económica. En definitiva, y utilizando las palabras de Miguel Ángel Ladero Quesada, «las llamadas ordenanzas municipales constituyen el término final de las formas medievales del derecho local» ${ }^{4}$. Su vigencia, adaptándose a las necesidades del momento, se ha mantenido en el tiempo, de hecho llegan hasta nuestros días. En el Real Decreto Ley 781/86 se esta-

\footnotetext{
${ }^{1}$ BAReIA, Roque, Primer diccionario general etimológico de la Lengua Española», 3, Madrid $1881,1043$.

${ }^{2}$ Artola, Miguel, Enciclopedia de la Historia de España., 5, Madrid 1988-1993, 887.

${ }^{3}$ Corral García, Esteban, Ordenanzas de los concejos castellanos: formación, contenido y manifestaciones (siglos XIII-XVIII), Burgos 1987, 37.

${ }^{4}$ Ladero Quesada, Manuel F., Las ciudades de la Corona de Castilla en la Baja Edad Media, Madrid 1996.
} 
blece que «en la esfera de su competencia, las Entidades Locales podrán aprobar ordenanzas y reglamentos y los alcaldes dictar bandos».

El contenido de las ordenanzas es muy extenso y variado ya que afectan a innumerables aspectos de la vida cotidiana. A la hora de establecer una clasificación para las mismas, se pueden establecer dos criterios:

Si se tiene en cuenta su origen se pueden clasificar en: ordenanzas reales, señoriales, de los concejos, gremiales y de los estamentos. De todo este grupo las más típicas, y por supuesto más numerosas, son las de los concejos que tratan sobre materias propiamente municipales y que el propio concejo elabora y forma.

Si se tiene en cuenta la amplitud de las materias que tratan se pueden establecer dos tipos de ordenanzas: aquéllas que tienen como objetivo la ordenación total de la población en su conjunto o aquéllas que tienen como objetivo la reglamentación de una parte o materia concreta. Es decir, existen ordenanzas generales que afectan a los principios que inspiran la convivencia de la villa y existen también ordenanzas particulares que tratan sobre aspectos concretos. En Ourense se conservan, en la época estudiada, normativas que reglamentan el conjunto de la villa -las ordenanzas de la ciudad correspondientes a los años 1427 y 1508-, y otras, la mayoría, que se refieren a temáticas concretas -el ordenamiento para la construcción del muro y la cerca de la ciudad, y todas las ordenanzas extraídas de los libros de acuerdos: ordenanzas del vino, de los carniceros, de los testamentos, etc.-. Se trata de ordenanzas que se aprueban de forma aislada y ocasionalmente para hacer frente a problemas o cuestiones que es preciso ordenar y resolver sin demora.

\section{POTESTAD NORMATIVA}

Los distintos estudios publicados hasta el momento señalan la existencia de ordenanzas impuestas por el rey o señor, de otras concordadas y otras que son obra exclusiva de los concejos, siendo este último, en la mayoría de los casos, el titular de la potestad normativa. El caso orensano no es una excepción siendo el concejo el principal protagonista en lo referente a la promulgación de ordenanzas, aunque sujeto al control de la jurisdicción señorial.

Del análisis detallado de las ordenanzas conservadas de la ciudad de Ourense en el siglo XV se deduce que están presentes todos los posibles titulares de los que antes se hacía mención: 


\begin{tabular}{|l|c|}
\hline \multicolumn{1}{|c|}{ TITULARES } & NÚMERO ORDENANZAS \\
\hline Señor (obispo) & 1 \\
\hline Corregidor (representante del rey) & 2 \\
\hline Concertadas: concejo-obispo & 32 \\
\hline Concejo & 33 \\
\hline
\end{tabular}

Este cuadro permite afirmar que, a la hora de dictar las ordenanzas, el principal protagonista era el concejo. Éste estaba presente en la mayoría de los casos, bien actuando aisladamente, en 33 ocasiones, bien, puesto que Ourense es un señorío episcopal, en ordenanzas concordadas con el obispo, 32 ordenanzas más. Por otra parte, el obispo, como señor jurisdiccional, podía también asumir y ostentar la potestad de la ordenanza, de una forma directa y sin intervención del concejo, potestad de la que hizo uso en ocasiones ${ }^{5}$. Por último, también se observa la existencia de ordenanzas impuestas por el rey a través de sus representantes, en este caso el corregidor, pero de las que sólo se conservan dos.

Dentro del concejo la potestad normativa la ostentaba la asamblea. En el caso orensano ésta recaía sobre los órganos rectores del concejo: alcaldes, regidores, jueces, procurador y hombres buenos. Por su parte el obispo, cuando no actuaba personalmente, delegaba en algunos miembros de su cabildo: vicario general o representante directo del obispo, arcedianos, canónigos, racioneros etc. El rey, por su parte, actuaba a través de su representante en los concejos: el corregidor ${ }^{6}$.

La potestad normativa, independientemente de quien fuera su titular, permitía confeccionar o dictar de nuevo las ordenanzas, reformar las antiguas o recopilar las vigentes.

\section{PROCEDIMIENTO DE ELABORACIÓN}

El procedimiento de elaboración lo ponía en marcha, en la gran mayoría de los casos el concejo, en ocasiones en solitario «logo os ditos rejedores e juises e procurador e omees ordenaron sobre rason das carnes en esta maneira que se sigue» ${ }^{7}$

${ }^{5}$ A.H.P.OU. Concellos, Libro IV, 67 v.-68. 1451. Ordenanza sobre el orden de las cofradías en la procesión del Corpus.

${ }^{6}$ En estos momentos Ourense no contaba con un corregidor propio. Gomes Días de Vasurto, era «correjedor por noso señor el rey enos obispados de Ourense e Tuy». El nombramiento de un corregidor para la ciudad de Ourense no se produjo hasta al siglo XVI.

${ }^{7}$ A.H.P.OU. Concellos. Libro I, 16-17r. 1432. Ordenanza de los carniceros. 
y en otras en concierto con el obispo: «sendo juntados en cabiidoo e conçello... feseron e ordenaron todos juntos estas ordenanças» ${ }^{8}$. Sin embargo, no faltaron casos en los que era el obispo el que tomaba la iniciativa y mandaba realizar la ordenanza: «logo, os ditos juises et rejedores et procurador, diseron que de mandado do noso señor obispo de Ourense»9.

En cuanto al procedimiento de elaboración es muy poca la información que aportan los documentos, aunque éste debería ser simple: en la mayoría de los casos el concejo, bien en solitario o con el cabildo, y tras discutir el tema y realizar una valoración de la conveniencia, llevaría a cabo la redacción, la cual correría a cargo de los oficiales del concejo o de los representantes del cabildo y el concejo, para posteriormente ser aprobadas. En el acta se transcribía, por lo general, el texto y al mismo tiempo se ordenaba la publicación mediante pregón que se realizaría, como se verá más adelante, en plazas y lugares acostumbrados.

Sin embargo, también existen algunos indicios que apuntan hacia la idea de que pudieran existir comisiones redactoras. Estas comisiones serían ampliamente representativas ya que estarían integradas tanto por los representantes del concejo como por los representantes del cabildo, en aquellos casos en los que se tratase de una ordenanza concertada con el obispo. Sirva como ejemplo el siguiente párrafo:

«logo o dito cabidoo e conçello feseron ordenança en esta maneira, por rason que en este ano se perderan as nouidades dos viños, en esta dita çidade e coutos e non ay y mantemento de viños para os vesiños e moradores da dita çidade et benefiçiados da dita iglesia, e para aveeren sobre elo acordo et remedio, se se deuian de trager de fora uo non e como avian de remedyr sobre elo, por ende, poseron omees boos do dito conçello e do dito cabiidoo para que o determinasen e remediasen, os quaes logo nomearon en esta maneira: Martin Sanches, abade da Triindade, et Manuel Afonso, tesoureiro et Pedro Sanches, arçediano de Baronçelle et Aluaro Ferrandes e Rodrigo Afonso, coengos et estes por parte do cabiidoo. Et por parte do conçello Meen Suares, Garçia Vaasques, Martin de Trella, Juan Peres de Rioseco e Vasco Afonso, Aluaro Peres, notario, Juan Ferrandes, prateiro, Ares de Doade, Pedro de Temees» ${ }^{10}$.

Así pues, en este caso, tanto el concejo como el cabildo nombraron a sus respectivos representantes para que estudiasen el tema y tratasen de dar solución al problema por medio de una ordenanza. En estas comisiones también debía de ser frecuente la presencia de representantes del oficio o actividad que en ese momento

\footnotetext{
${ }^{8}$ A.H.P.OU. Concellos, Libro I, 28. 1432. Ordenanza sobre la provisión de vinos.

${ }^{9}$ A.H.P.OU. Concellos, Libro IV, 82-83. 1452. Pregón de la ordenanza en la cual se prohibe asistir a las ferias de Pedrayo, Bruñal y Pereiro.

${ }^{10}$ A.H.P.OU. Concellos, Libro I, 21-22. 1432. Ordenanza de los vinos.
} 
se estaba reglamentando, ya que es habitual encontrar, por ejemplo, carniceros en ordenanzas que hacen referencia a las carnes «Pedro Rodrigues, Juan de Deus, Aluaro Ferrandes, carniçeiros» ${ }^{11}$, y lo mismo con otras profesiones.

Una vez que la ordenanza había sido confeccionada debía ser remitida al obispo y al concejo para su aprobación, en el caso de que fuera concordada: «despois desto, a quatro dias de nobenbro de LIII foy confirmadas estas ordenanças por los rejedores e juises da dita çidade et por lo vigario do noso señor obispo» ${ }^{12}$.

En los casos en los que el concejo actuaba sólo, sin la intervención del cabildo, éste debía remitir las ordenanzas que acordara al señor jurisdiccional, es decir al obispo, para que las confirmara «e mays foy noteficado ao dito señor obispo todas las outras hordenanças e o dito señor obispo diso que as confirmaba» ${ }^{13}$.

\section{ESTRUCTURA DE LAS ORDENANZAS}

La estructura de las ordenanzas suele ser básicamente la misma:

Por regla general, como encabezamiento o preámbulo, aparece el acta de la sesión en la que se aprobaron. En ella se indica la fecha y el lugar en que ésta tiene lugar, así como los titulares sobre los cuales recae la potestad normativa para realizar la ordenanza. Estas actas revelan una concurrencia numerosa de regidores y demás oficiales del concejo (jueces, procurador, notario). Cuando se trata de una ordenanza concertada con el obispo, junto con el concejo aparece un grupo numeroso de representantes del cabildo.

A continuación sigue el texto íntegro de la ordenanza, sin ordenar en libros, capítulos, artículos ni en ninguna otra forma. En la mayoría de los casos se trata de una disposición bien prohibitiva, bien impositiva, de una conducta determinada, cuyo incumplimiento está castigado con una multa, generalmente pecuniaria, aunque tampoco faltan las penas corporales y de cárcel.

La tercera parte es aquélla en la que queda constancia de la forma en que se ha dado cumplimiento a la publicación ${ }^{14}$.

Finalmente aparece una relación de testigos.

Es de destacar que en algunas ocasiones se puede observar como antes de dictar la ordenanza se explica el problema o cuestión que es preciso ordenar o resolver.

\footnotetext{
${ }^{11}$ A.H.P.OU. Concellos, Libro I, 39 r. 1433. Ordenanza sobre las carnes.

12 A.H.P.OU. Concellos, Libro IV, 73 v.-74. Ordenanza de los zapateros.

${ }^{13}$ A.H.P.OU. Concellos, Libro IV, 60 v.-61 r. 1452. Ordenanza sobre los vinos de fuera.

${ }^{14}$ En las ordenanzas extraídas de los libros de acuerdos (minutarios notariales del escribano del concejo) falta, en ocasiones, la parte correspondiente al encabezamiento y publicación.
} 


\section{CONTENIDO}

En las ordenanzas municipales de Ourense quedan recogidas las principales preocupaciones del concejo de la ciudad de Ourense y en ellas se regulan los distintos aspectos de la vida local: orden público, oficios, abastos, urbanismo, limpieza, precios, salarios, etc.

Las ordenanzas orensanas se pueden desglosar en distintos bloques temáticos, pero siguiendo a Esteban Corral ${ }^{15}$, se han reducido a los siguientes:

- Organización y funcionamiento del concejo

- Policía urbana

- Policía rural

- Abastos y precios

- Actividad económica y comercial

- Hacienda

- Otras materias

\section{Organización y funcionamiento del concejo}

Al contrario de lo que ocurre en otras localidades castellanas, Ourense conserva, para el período estudiado, muy pocas ordenanzas que traten sobre la organización y funcionamiento del concejo. Tan sólo se conservan tres correspondientes a los años 1432, 1452, 1508 ${ }^{16}$. En ellas se hace mención a las reuniones del concejo, y cada una aporta una pequeña información adicional a la anterior que, combinadas con las informaciones contenidas en otras ordenanzas relativas a otros temas, permiten tener una visión de la estructura concejil y de su funcionamiento.

El concejo de Ourense, de acuerdo con la ordenanza de 1452, estaría formado por: dos jueces o alcaldes nombrados por el obispo entre los seis «omes boos» que presenta el concejo; los hombres buenos, en número equivalente al de gremios de menestrales, eran consultados por el concejo para aquellos asuntos que afectaban al interés general; cuatro o cinco regidores nombrados por el obispo entre los vecinos de la ciudad; un procurador elegido por los representantes elegidos por los vecinos, cuya función era representar a la vecindad ante el obispo, los tribunales y el rey; y un notario o escribano para dar fe y dejar constancia de lo allí tratado.

\footnotetext{
15 Corral García, Esteban, Ordenanzas de los concejos castellanos: formación, contenido y manifestaciones (S. XIII-XVIII), Burgos 1998.

${ }^{16}$ A.H.P.OU. Concellos, Libro I, 4 v. 1432. Ordenanza sobre las reuniones del concejo.

A.H.P.OU. Concellos, Libro IV, 61 r.. 1452. Ordenanza sobre las reuniones del concejo.

A.H.P.OU. Concellos, Libro VII, 1 r. 1508. Ordenanza sobre las reuniones del concejo.
} 
En lo referente a las reuniones, se sabe que a partir del reinado de Alfonso XI el concejo debía reunirse dos días a la semana: lunes y viernes ${ }^{17}$. En Ourense, no se vuelve a tener noticias sobre el día de reunión del concejo hasta la ordenanza de 1432, donde aparece regulado que el concejo se reúna los jueves: «ordenaron mays os ditos rejedores que cada quinta feira se ajuntaren conçello, en Santa Maria Madre, a ora terça, segundo era de vso e custume de en tenpo antigoo dese ajuntar» ${ }^{18}$. La finalidad que se buscaba al fijar un día y una hora concreta no era otra que tratar que los asuntos se resolvieran regularmente y que los vecinos tuvieran conocimiento de ello.

El jueves como día de reunión se mantuvo a lo largo de tiempo. Así queda recogido en las ordenanzas de 1452 y 1508 . Varía, sin embargo, la hora. En 1432 se reunían a la hora «terça», pero en 1452 se establece que la hora de reunión sea «a ora prima e terça fasta oras de misa grande» ${ }^{19}$.

En cuanto al lugar de reunión, la ordenanza de 1432 establecía que debía celebrarse en Santa María Madre. Sin embargo, a partir de ese año, son muy pocas las actas del concejo en las que se mencione este lugar como punto de reunión, existiendo otros puntos de la ciudad donde se reunió el concejo: en la Catedral $^{20}$; en otras iglesias de la ciudad; en las plazas ${ }^{21}$; o, incluso, en casas particulares ${ }^{22}$.

A partir de 1480, y por un mandato de los Reyes Católicos, se fue generalizando en las ciudades la construcción de casas consistoriales como lugar de reunión de los regidores y residencia del corregidor. Sin embargo, en Ourense no existen noticias de la existencia de una casa destinada a reunión del ayuntamiento hasta comienzos del siglo $\mathrm{XVI}^{23}$.

La asistencia de todos los cargos a la reunión era obligatoria, pues la presencia de los regidores acompañados de los otros oficiales resultaba imprescindi-

${ }^{17}$ Información obtenída de un traslado notarial realizado por el concejo de Santiago en el año 1364, de la confirmación de Pedro I de un ordenamiento otorgado por Alfonso XI, en 1346, a las ciudades y villas del reino de Galicia, ordenando la celebración de concejos en todas las ciudades y villas. A.H.P.OU. Pergaminos, Carp. 22, n. ${ }^{\circ} 3$.

${ }^{18}$ A.H.P.OU. Concellos, Libro I, 4 v. 1432. Ordenanza sobre las reuniones del concejo.

${ }^{19}$ A.H.P.OU. Concellos, Libro IV, 61 r. 1452. Ordenanza sobre las reuniones del concejo.

${ }^{20}$ A.H.P.OU. Concellos, Libro I, 16-17 r. 1432. Ordenanza de los carniceros.

${ }^{21}$ A.H.P.OU. Concellos, Libro III, 16 v. 1442. Ordenanza y mandamiento sobre las blancas; A.H.P.OU. Concellos, Libro IV, 82-83. 1452. Pregón de la ordenanza que prohibe acudir a las ferias de Pedrayo y Bruñal.

22 A.H.P.OU. Concellos, Libro VI, 5 v. 1457. Pregón de la ordenanza de las armas; A.H.P.OU. Concellos, Libro IV, 92 v. 1453. Ordenanza de los carniceros; A.H.P.OU. Concellos, Libro III, 77 v. 1446. Ordenanza sobre los precios de las herrerías; A.H.P.OU. Concellos, Libro I, 36. 1433. Ordenanza sobre el pan de trigo y otros productos.

${ }^{23}$ Gallego Domínguez, Olga, «Las casas consistoriales de la ciudad de Orense», Boletín Aunense, 10, Orense 1980, pp. 107-117. 
ble para que la reunión del concejo tuviera capacidad legal. Sin embargo, era poco frecuente que todos los regidores acudiesen a las reuniones; las actas muestran la presencia de un número variable de los mismos, desde tres hasta cinco, llegándose en ocasiones a solicitar la anulación de la reunión por ausencia de sus miembros.

De las votaciones no se conoce nada, pues las actas parecen ofrecer en Ourense, como práctica, la conformidad de todos los reunidos: «logo todos ordenaron que», «ordenaron et mandaron que». Sólo en los casos en los cuales la ordenanza se concierta entre el cabildo y el concejo se señala que hubo acuerdo: «estando y presentes o dito señor et os juises et rejedores et procurador da dita çidade, logo o dito señor obispo, con acordo dos ditos juises e rejedores e procurador, ordenaron que por rason» ${ }^{24}$.

\section{Policía urbana}

Las normas relativas a urbanismo, salubridad y orden público, constituyen el contenido típico de la «policía urbana».

\section{Urbanismo}

El urbanismo es una de las preocupaciones básicas del gobierno municipal. El concejo trata de desarrollar actuaciones urbanísticas positivas en orden a la configuración, trazado de calles y uniformidad de edificaciones. Además persigue facilitar la circulación de las personas y mercancías, así como el normal desarrollo de las actividades urbanas. Los vecinos, por su parte, tratan de ganar la calle y otros espacios públicos para su uso particular. Un claro ejemplo de esta situación se encuentra en una ordenanza de 1427 que, a pesar de estar incompleta, parece indicar la prohibición de realizar voladizos o balcones sobre las calles: «et outrosy ordenamos algun nen alguns non seja ousado de fazer [...] sobre la rua. Et se a touer feyta que a tire, supena de dez maravedis por cada vez» 25 .

Las infracciones urbanísticas debían de ser muy frecuentes, pues son muchas las veces que las autoridades municipales intervienen para ponerles remedio. Así, en algunos casos, procedían a echar a bajo las obras ilegales, como por ejemplo unos balcones que sobresalen más de lo permitido ${ }^{26}$; en otras ocasiones, se procedía al

${ }^{24}$ A.H.P.OU. Concellos, Libro I, 138 r.-139. 1437. Ordenanza sobre el orden de las cofradías en la procesión del Corpus.

${ }^{25}$ Martínez SueIro, Manuel, «Fueros municipales de Orense» Boletín de la Comisión Provincial de Monumentos Históricos y Artísticos de Orense, IV, Orense 1911, 81.

${ }^{26}$ A.H.P.OU. Concellos, Libros I, p. 53. 
derribo de obras que consideraban que entrañaban un peligro para sus vecinos, o suponían un perjuicio para el concejo ${ }^{27}$; y, en algunos casos, se llegaba a la paralización inmediata de la obra que iría seguida de un informe sobre su ilegalidad y eventual demolición ${ }^{28}$.

La utilización particular de los ríos también estaba sujeta a la reglamentación municipal, de forma que ciertas obras no chocasen con los intereses colectivos. Así, por ejemplo, en 1438 se prohibía hacer «caneiros» en los ríos: «ordenaron e mandaron que persona nenhua non fesese caneyros des onde se junta agoa da Baruaña ao muyño, fasta en todo o rio da barbaña, so pena de los derribaren e os desfaseren et pagaren por cada vez que os fisesen sesenta maravedis de pena» 29 .

Otra de las preocupaciones del concejo era mantener en buen estado la apariencia de las vías públicas, aunque también hay que señalar que, normalmente, lo que hacía era trasladar el problema a los vecinos, los cuales, de acuerdo con una ordenanza de 1508, estaban obligados a reparar el empedrado de las calles durante el mes de diciembre: «e que cada vno sea obligado de corrojer e reparar el enpedrado cada vno ante ante (sic) sus puertas de sus casas e de sus bodegas» ${ }^{30}$.

Las penas impuestas para quienes no cumpliesen con las normas son pecuniarias y en algunos casos, como en el de los «caneiros», la sanción lleva implícita la destrucción de la obra que ha sido objeto de la infracción.

\section{Salubridad}

La policía urbana se ocupaba también de normas relativas a la salubridad, donde se trataban aspectos como la limpieza de las calles; se establecían prohibiciones, por ejemplo, no verter aguas sucias, no hacer estercoleros, no dejar animales sueltos por las calles; o se establecían normas que regulasen las medidas de higiene en establecimientos, lavado de ropas y paños, etc. Todo ello con el fin de tratar de evitar molestias al vecindario y conseguir la higiene y realce de la ciudad.

Ourense, al igual que otras ciudades castellanas, muestra una gran preocupación por el problema de la higiene pública y para ello:

Se aprueban ordenanzas relativas a la limpieza de las calles, en las que se regulan los días y la forma en que deben hacerlo los vecinos, «asy durante el dicho tenpo en los dichos meses, cada sabado, sean obligados de alinpiar las calles e los

${ }^{27}$ MartíneZ Sueiro, Manuel, «Fueros», IV, Orense 1911, 81.

${ }^{28}$ A.H.P.OU. Concellos, C-526, n. ${ }^{\circ} 75$.

${ }^{29}$ A.H.P.OU. Concellos, Libros II, 12 v. 1438. Ordenanza sobre los «caneyros».

${ }^{30}$ A.H.P.OU. Concellos, Libros VII, 2 v.-3 r. 1508. Ordenanza sobre la limpieza y el arreglo de las calles. 
portales de sus casas e ante sus vodegas» ${ }^{31}$; a las medidas de higiene que se debían de adoptar en los establecimientos públicos, como, por ejemplo, durante el verano limpiar la carnicería todos los viernes ${ }^{32}$, o a la prohibición de lavar en fuentes públicas de la ciudad ${ }^{33}$.

Se prohibe tirar basuras y desperdicios a las calles y plazas; construir establos en las mismas ${ }^{34}$; introducir en la ciudad animales como ovejas, patos, cabras, bajo la pena de una multa económica y la perdida de los animales, «ningunas presonas non tengan dentro de la çibdad ningunas obejas, ni cabras, ni pactos» ${ }^{35}$; se reglamenta sobre los estercoleros y las piaras ${ }^{36}$; y se establece dónde se deben verter las aguas sucias ${ }^{37}$.

Se separa a los enfermos contagiosos, o considerados socialmente repelentes, a los que se solía recluir en lugares fuera de la villa. Por ejemplo, en una ordenanza de 1497, se prohibe a los mesoneros que acojan en sus establecimientos a ningún enfermo y, en caso de tenerlo hospedado, que lo comuniquen inmediatamente al concejo para que sea examinado: «esta hordenado que ningund mesonero acoja $\mathrm{ni}$ rresçiba en su casa ni mesón ningund físico e posando en el que lo hagan saver a la justiçia e rregimiento para que los hagan esaminar, so pena de sesenta maravedis» ${ }^{38}$.

\section{Orden Público}

Otra de las preocupaciones del concejo era la salvaguarda del orden público en la ciudad. Para ello se adoptaron una serie de medidas que se hacían más estrictas en los momentos de tensión. Entre ellas, y variando según la situación de cada momento, figura la prohibición de poseer armas ${ }^{39}$, así como las personas que están eximidas de esta prohibición ${ }^{40}$; la prohibición de entrar en la ciudad a todos aque-

\footnotetext{
${ }^{31}$ A.H.P.OU. Concellos, Libros VII, 2 v.-3 r. 1508. Ordenanza sobre la limpieza y el arreglo de las calles.

32 Martínez Sueiro, Manuel, «Fueros», IV, Orense 1911, 80-5.

${ }^{33}$ Martínez Sueiro, Manuel, «Fueros», IV, Orense 1911, 80-5.

${ }^{34}$ A.H.P.OU. Concellos, Libros VII, 2 v.-3 r. 1508. Ordenanza sobre la limpieza y el arreglo de las calles.

${ }^{35}$ A.H.P.OU. Concellos, Libro VII, 3 r. 1508. Ordenanza que prohibe la entrada en la ciudad de ovejas, cabras y patos.

36 A.H.P.OU. Concellos, Libros I, 190. 1435. Ordenanza sobre los puercos y los establos.

37 Martínez SueIro, Manuel, «Fueros» IV, Orense 1911, 80-5.

38 A.H.P.OU. Concellos, Libro 244, 50 v. 1497. Ordenanza sobre los mesoneros.

${ }^{39}$ A.H.P.OU. Concellos, Libros II, 56 v. 1440. Pregón de la ordenanza sobre los casquetes, ballestas y dardos.

${ }^{40}$ A.H.P.OU. Concellos, Libro VI, 5 v. 1457. Pregón de la ordenanza de las armas.
} 
llos que pudieran perturbar el orden ${ }^{41}$; se ordenaba la vigilancia nocturna diaria y, cuando la tensión era muy fuerte, se establecían toques de queda durante la noche ${ }^{42}$; se ocupaban también de la vigilancia de las murallas, ordenando que «se çerrasen as portas da vyla aqueles que tiñan as chaves das portas» ${ }^{43} \mathrm{y}$ de la persecución de delincuentes.

Las multas para los que incumplieran alguna de estas ordenanzas eran fundamentalmente de carácter económico, aunque también son frecuentes las penas de cárcel, la confiscación de las armas y, en ocasiones excepcionales, como en la ordenanza de los vagabundos, se observa la presencia de sanciones físicas, como los azotes.

\section{Policía rural}

La policía rural era la encargada de las funciones relativas a la regulación y ordenación de la vendimia, de la guarda y vigilancia de las viñas, bacelos ${ }^{44}$, huertas y cortiñas ${ }^{45}$, y de los oficiales encargados de ello, los «couteiros», así como de establecer la prohibición, sanción y denuncia por la entrada y daños ocasionados por el ganado mayor y menor en fincas particulares, viñas, huertas, etc.

Los textos ponen de manifiesto la preocupación del concejo por asegurar la defensa de las tierras destinadas a la agricultura frente al ganado. Para ello se prohibía la entrada de animales en las viñas, por los grandes daños que ocasionan al provocar la pérdida de sus frutos ${ }^{46}$, y se autorizaba a los dueños de las mismas y a los oficiales encargados de la vigilancia a adoptar distintas medidas en función del tipo de animal del que se trate y del período del año, estableciéndose las penas más duras durante la época de vendimia ${ }^{47}$.

Por otra parte, las ordenanzas también regulan las intromisiones y robos causados por las personas, estableciendo la prohibición de entrar en las huertas, viñas, bacelos y cortiñas a coger frutos ${ }^{48}$ o robarlos. Prohibición que se hizo también extensiva a los instrumentos de cultivo ${ }^{49}$. Las penas impuestas iban desde las multas pecuniarias hasta las corporales como, por ejemplo, estar expuesto a la picota o ir a la cárcel.

\footnotetext{
${ }^{41}$ A.H.P.OU. Concellos, Libro 244, 53 r. 1531. Ordenanza sobre los vagabundos.

${ }^{42}$ A.H.P.OU. Concellos, Libros II, 32. 1438. Ordenanza que prohibe andar por la noche.

${ }^{43}$ A.H.P.OU. Concellos, Libros VI, 5 v. 1457. Pregón de la ordenanza de las armas.

44 Viñas nuevas.

45 Terreno cercado próximo a la vivienda, generalmente de pequeñas dimensiones, dedicado fundamentalmente al cultivo de cereales y hortalizas.

${ }^{46}$ A.H.P.OU. Concellos, Libro I, 125. 1435. Ordenanza sobre los animales que entran en las viñas.

${ }^{47}$ A.H.P.OU. Concellos, Libro I, 125. 1435. Ordenanza sobre los animales que entran en las viñas.

${ }^{48}$ A.H.P.OU. Concellos, Libro VII, 3 v. 1508. Ordenanza sobre los robos en las viñas.

${ }^{49}$ A.H.P.OU. Concellos, Libro VII, 3 v. 1508. Ordenanza sobre los robos en las viñas.
} 


\section{Política de abastos}

Un capítulo importante para la vida de la ciudad era el referente al abastecimiento de los productos básicos. Los concejos le dedicaban a este tema gran cantidad de ordenanzas, así como a los problemas que pudiera suscitar esta actividad, y Ourense, una vez más, no va a ser una excepción siendo esta materia una de las más extensamente reguladas por sus ordenanzas, hasta el punto de que se puede afirmar que, junto con las que reglamentan la actividad artesanal y comercial, suponen aproximadamente las $3 / 4$ partes de las ordenanzas conservadas.

A través de estas normas el concejo trata de que la ciudad esté bien abastecida de los productos alimenticios básicos, de ejercer un control sanitario sobre toda clase de alimentos y sobre su calidad, de evitar fraudes en el peso y fijar unos precios justos para los productos de mayor consumo y necesidad.

El concejo ejerce su control no sólo sobre los productos alimenticios básicos tales como el vino, la carne, el pescado, el pan o el aceite, sino que la actuación municipal se extiende mucho más allá, llegando a controlar otro tipo de productos tales como el sebo, el unto, las velas, etc. En todos ellos la fidelidad en el peso y la fijación de precios justos serán sus máximas preocupaciones.

El vino es un producto fundamental dentro de la economía orensana por lo que se ve ampliamente reflejado en sus ordenanzas. Éstas muestran una doble preocupación: por una parte, persiguen la protección del viñedo y de la producción vitícola, y por otra la defensa del mercado y de la producción interna frente a los vinos que venían de fuera ${ }^{50}$. Además ejercía un férreo control sobre la operación de encubar el vino -estableciendo que los que no eran vecinos no la podrían realizar ${ }^{51}$; sobre la venta del mismo -el concejo examinaba su calidad y en función de ello determinaba su precio ${ }^{52}$, o sobre el vino que en ese momento había en la ciudad -prohibiendo la apertura de nuevos barriles mientras que el anterior no se hubiera acabado $^{53}$.

La carne era otro de los productos que estaba sujeto a un fuerte control por parte del concejo. Éste organizaba y disponía todo lo referente al peso de las carnes ${ }^{54}$ y al precio de las mismas ${ }^{55}$ así como las medidas higiénicas donde se vendía.

El pescado también sufría la fuerte política intervencionista del concejo, tanto en lo referente a los pesos, al precio y calidad como a los lugares de venta. Ésta sólo

\footnotetext{
50 A.H.P.OU. Concellos, Libro I, 28. 1432.Ordenanza sobre la provisión de vinos.

51 A.H.P.OU. Concellos, Libro I, 103 v.-104 r. 1433. Pregón de la ordenanza de los vinos.

52 A.H.P.OU. Concellos, Libro I, 37 v.-38. 1433. Ordenanza sobre la venta del vino.

53 A.H.P.OU. Concellos, Libro VII, 2 r. 1508. Ordenanza de los vinos.

54 A.H.P.OU. Concellos, Libro I, 103. 1434. Ordenanza sobre los pesos de los carniceros.

55 A.H.P.OU. Concellos, Libro III, 81 v.-82 r. 1446. Ordenanza sobre los carniceros.
} 
se podía llevar a cabo en la Plaza del Pescado, estando prohibida realizarla en casas particulares ${ }^{56}$, aunque en ocasiones y por ciertos períodos de tiempo, se establecieron otros puntos de venta ${ }^{57}$.

El pan, producto fundamental para la dieta alimenticia, al igual que los anteriores está fuertemente controlado por el concejo. Los precios eran fijados sobre la base del precio del grano ${ }^{58}$ y para su venta había de estar bien cocido y en su peso correcto. Además el concejo adoptó otras medidas tales como la prohibición de sacar pan y grano de la ciudad ${ }^{59}$; la obligación de venderlo en una plaza pública ${ }^{60}$; o la prohibición de comprarlo fuera de la plaza.

Con el aceite, el concejo adopta la misma política intervencionista fijando su precio «que el açumbre de azeyte se benda a rreal y medio y no a mas, so pena de lo perder e pagar sesenta maravedis por cada vez» ${ }^{61}$; señalando los pesos y medidas ${ }^{62}$; estableciendo el punto de venta, así como las condiciones en que ha de llevarse a cabo ${ }^{63}$; y, por último, como paso previo a su venta, tenía que ser revisado por los oficiales del concejo para comprobar su calidad: «que sea llamado el rregidor que fuere beedor de las hordananças para ver si hes bueno» ${ }^{64}$.

\section{Actividad artesanal y comercial}

En Ourense, las ordenanzas ponen de manifiesto la existencia de varias cofradías de oficio, vinculadas generalmente a una iglesia de la ciudad, que concentraban una determinada actividad artesanal: Santa María Madre, vinculada a los comerciantes y sastres ${ }^{65}$; Santa Eufemia, a los zapateros; Santa María Magdalena, a los carniceros; San Miguel, a los herreros; y las de San Sebastián y la del Cuerpo Santo de las que no existe constancia documental de a quién pertenecían.

El comercio estaba fuertemente regulado. Ya se vió como el concejo fijaba los precios y medidas para cada producto, y como señalaba los lugares donde estaba autorizada su venta. De igual forma se establecía la prohibición conforme a la cual

\footnotetext{
${ }^{56}$ A.H.P.OU. Concellos, Libro II, 59 v. 1441. Ordenanza sobre el «almoraçer» del pescado.

${ }^{57}$ A.H.P.OU. Concellos, Libro 244, 53 v. 1485. Ordenanza sobre la venta del pescado.

${ }^{58}$ A.H.P.OU. Concellos, Libro I, 36. 1433. Ordenanza sobre el pan de trigo y otros productos.

${ }^{59}$ A.H.P.OU. Concellos, Libro VI, 33. 1458. Ordenanza del pan.

${ }^{60}$ A.H.P.OU. Concellos, L. 244, 53 v. [S.A.]. Ordenanza sobre la venta del pan.

${ }^{61}$ A.H.P.OU. Concellos, Libro 244, 51 v. [S.A.]. Ordenanza sobre el precio del aceite.

62 A.H.P.OU. Concellos, Libro 244, 51 v. [S.A.]. Ordenanza sobre las medidas del aceite.

${ }^{63}$ A.H.P.OU. Concellos, Libro 244, 53 v. [1509]. Ordenanza sobre la venta del aceite.

${ }^{64}$ A.H.P.OU. Concellos, Libro 244, 51 v. [S.A.]. Ordenanza sobre la venta del aceite.

${ }^{65}$ Cofradía que ha pervivido hasta el primer cuarto del siglo XX, como prueba la documentación conservada en el A.H.P.OU., que se extiende desde mediados del siglo XVII a principios del XX.
} 
los extranjeros no podían abrir tiendas ni ejercer ningún oficio hasta que se presentaran en concejo y se convirtieran en vecinos ${ }^{66}$.

Asimismo controlaban todos los aspectos referentes a las ferias. En el siglo XV se asiste a una intensificación de los intercambios comerciales. Prueba de ello es la celebración de ferias anuales que aparecen reguladas por las ordenanzas. Juan I había concedido al obispo don Pascual, en 1386, una feria anual. Ésta comenzaba el día de San Facundo y San Primitivo, tenía una duración de 15 días y se ubicaba alrededor del «Castelo Ramiro», es decir, en las proximidades de la ciudad ${ }^{67}$. Años más tarde, por una ordenanza de 1435, se establece que comience tres días antes de San Martiño y que tenga una duración de quince días ${ }^{68}$; y, en 1448, por otra ordenanza, se traslada al centro de la ciudad, a la Plaza del Campo ${ }^{69}$.

\section{Hacienda}

El mantenimiento de su propia administración debió constituir un capítulo muy abultado del presupuesto municipal, a lo que hay que añadir otros gastos ocasionados por la reparación de los baños ${ }^{70}$, de algunas fuentes ${ }^{71}$, la construcción de la cerca $^{72}$, y las distintas reconstrucciones del puente sobre el río Miño ${ }^{73}$. Para afrontar todas estas necesidades el concejo contaba con varios recursos: por un lado, el arrendamiento del cobro de algunos tributos de la Corona, como los pedidos ${ }^{74} \mathrm{y}$ alcabalas $^{75}$-el concejo era el responsable de su cobro y procedía a subastarlo entre particulares, obteniendo de esta forma unos ingresos periódicos-. Por otro lado, contaba con el cobro de multas por infracciones de la normativa municipal, además de los repartimientos y sisas.

\footnotetext{
66 A.H.P.OU. Concellos, Libro 244, 53 r. 1531. Ordenanza sobre el comercio.

${ }^{67}$ Durany Castrillo, Mercedes, «Ourense na Idade Media». En Historia de Ourense. A Coruña , 1996, p. 147.

${ }^{68}$ A.H.P.OU. Concellos, Libro I, 190. 1435. Ordenanza sobre la feria de San Martiño.

${ }^{69}$ A.H.P.OU. Concellos, Libro IV, 8. 1448. Ordenanza sobre la feria de San Martiño.

70 A.H.P.OU. Concellos, Libro IV, 123. 1454. Ordenanza sobre los baños.

${ }^{71}$ A.H.P.OU. Concellos, Libro I, 73 r. 1434. Ordenanza sobre la obra de la fuente y pilo de Fonte Arcada.

${ }^{72}$ A.H.P.OU. Concellos, C-127/22. 1388. Ordenamiento para la construcción de la cerca y muro de la ciudad.

${ }^{73}$ A.H.P.OU. Concellos, Libro I, 50 v.-51, 54 r.-55 r. 1433. Ordenanzas para ayudar a realizar el puente de Ourense.

${ }^{74}$ A.H.P.OU. Concellos, Libro I, 102 v.-103 r. 1434. Ordenanza sobre Gonçalo Yanes.

${ }^{75}$ A.H.P.OU. Concellos, Libro IV, 82-83. 1452. Pregón de la ordenanza que prohibe acudir a las ferias de Pedrayo, Bruñal y Pereiro.
} 


\section{Otras materias}

Las ordenanzas, además de ocuparse de la organización administrativa, de la policía y de vida económica, también reglamentan múltiples aspectos relativos al discurrir cotidiano de esta ciudad medieval tales como los precios de los mesones $\mathrm{y}$ tabernas, testamentos y exequias.

Los mesones, lugares destinados a ofrecer comida y hospedaje, eran sometidos a una fuerte presión por el concejo, siendo éste quien establecía el precio que se debía cobrar por la cebada, paja, vino, pan,... que vendiesen a sus huéspedes. Todos los precios debía ser expuestos en un arancel, firmado por el escribano del concejo, en un lugar público para que todos lo viesen a fin de que nadie pudiera alegar ignorancia y así evitar controversias. La pena establecida para los infractores consistía en una sanción económica y tres días de cárcel.

La conservación de una ordenanza relativa a la redacción de testamentos permite conocer las condiciones en las que éstos se redactaban. Con anterioridad a esta ordenanza los testamentos pasaban por los notarios, pero no se podía proceder a su firma sin que antes pasasen por delante del chanciller de la iglesia. El problema se planteó por que «o dito chançeller leuaua grandes contias de maravedis et por sy meesmo os taixaua como lle prasia et en mays grandes contias de maravedis que os ditos testamentos meresçian auer de seu salario et dauan aos notarios por quen pasauan pouco selario, leuando el o traballo et o dito chançeller leuando a dema$o s i a »^{76}$. Esto trajo como consecuencia que los vecinos se abstuviesen de realizar testamentos. Ante esta situación el concejo intervino promulgando una ordenanza en la cual regulaba los precios por redactar testamentos, estableciendo un tope máximo de 60 maravedís para aquellos testamentos que recojan fortunas considerables, mientras que la retribución fijada por redactar testamentos de menor cuantía se establecía en función de los bienes dejados en herencia por el difunto. Los honorarios resultantes debían ser repartidos por el notario y chanciller a partes iguales

Aunque las ordenanzas relativas a enterramientos y exequias corresponden a los primeros años del siglo XVI, la primera es de 1505 , y las otras no son más que dos breves regestos de ordenanzas correspondientes a 1512 y 1513, vienen a confirmar la idea que el concejo trata de dar solución a un problema municipal a través de la promulgación de una ordenanza.

El problema residía en la larga duración de las honras fúnebres, nueve días, lo que suponía, por una parte, un gasto económico considerable para sus familiares (pago de misas, velones, etc.) y, por otra, les obligaba a descuidar sus hacien-

\footnotetext{
${ }^{76}$ A.H.P.OU. Concellos, Libro I, 192 v.-193 v., 107 r. 1434. Ordenanza sobre los testamentos.
} 
das ${ }^{77}$, con la consiguiente pérdida económica. Por lo tanto, el concejo ordena que las honras fúnebres se reduzcan a tres días.

\section{PUBLICACIÓN}

La publicación de una ordenanza cumplía una doble finalidad: dar a conocer la existencia y contenido íntegro de la norma, hasta el punto de que en el pregón se realizaba una lectura íntegra del texto; y no poder alegar con posterioridad como causa de incumplimiento la ignorancia: «e ninguno delles podese pretender nin alegar ynorançia» ${ }^{78}$, «Et, por que os huuns nen os outros non sejan delo ynorantes, que o mandan asy apregoar por as praças e merqados desta dita çidade» ${ }^{79}$.

Así pues, la publicación se convirtió en un trámite esencial y, con el transcurrir del tiempo, se tendió a darle una mayor solemnidad.

La forma más habitual de hacer la publicación fue a través del pregón, que se hacía a «altas voses» en las plazas o en los mercados, sitios donde la concurrencia de gente era mayor: «se deu pregon ena maneira sobredita por Diego Ferrandes, pregoeiro, altas voses, ena praça do Canpo» ${ }^{80}$; por las puertas de la ciudad: «et foy asy apregoado por las puertas da dita çidade por Diego Ferrandes, pregoeiro, et por min, o dito notario» ${ }^{81}$; en las casas de algún vecino relevante: «se mando poner e pregar lo susodicho en portas de las casas de Pedro de Lemos, que son sytas» ${ }^{82}$; e, incluso, en ocasiones se les comunicaba directamente a los afectados: «E que fosen luego os ditos juezes e procurador ao noteficar aos ditos carniçeiros» ${ }^{83}$.

Los pregones debían realizarse siempre ante el notario, que da fe del acto, y con la presencia de testigos: «Et logo, en este dito día e ora, o dito Diego Ferrandes, pregoeiro, ante min, o dito notario, a altas voses deu hun pregon ena Praça do Canpo... Testemuyas: Pedro Rodrigues, Nuno Patiño, Pascoal Rodrigues, Lourenço Diegues» ${ }^{84}$.

\footnotetext{
${ }^{77}$ A.H.P.OU. Concellos, C-527/22. 1505. Ordenanza sobre los enterramientos y las exequias.

${ }^{78}$ A.H.P.OU. Concellos, C-527/22. 1505. Ordenanza sobre los gastos de los entierros y exequias.

${ }^{79}$ A.H.P.OU. Concellos, Libro I, 84. 1434. Ordenanza sobre los vinos de Portugal.

${ }^{80}$ A.H.P.OU. Concellos, Libro I, 84. 1434. Ordenanza sobre los vinos de Portugal. Se comprueba asimismo como también fue pregonada en las Plazas del Campo, de la Carnicería, del Pescado, en la «Rua da Ayra», en la «Crus do Centeo» y en la «Crus dos Ferreiros», es decir por las principales plazas y encrucijadas de la ciudad.

${ }^{81}$ A.H.P.OU. Concellos, Libro I, 103 v.-104. 1434. Pregón de la ordenanza de los vinos.

${ }^{82}$ A.H.P.OU. Concellos, Libro 244, 50. [S.A.]. Ordenanza sobre el pescado remojado.

${ }^{83}$ A.H.P.OU. Concellos, Libro IV, 60 v. 1452. Ordenanza de las carnes.

${ }^{84}$ A.H.P.OU. Concellos, Libro I, 16-17 r. 1432. Ordenanza de los carniceros.
} 


\section{VIGENCIA}

La entrada en vigor de una nueva ordenanza suponía que su texto adquiría fuerza y vigor de ley, la revocación de las anteriores y confería al concejo la facultad para aplicar las sanciones en ella contenidas.

Por otra parte, una vez que entraba en vigor, está prohibido llevar a cabo en ellas cualquier tipo de cambio sin antes cumplir con los trámites establecidos de antemano, ya que la facultad de interpretar y derogar correspondía al que las establecía: «Otrossi, ordenamos que a saluo finque a nos, el dicho obispo, para que con conseio de los dichos omes buenos de nuestro cabilldo et jueses e rregidores de nuestro conçejo, podamos en las dichas leys deste nuestro quaderno enader, corregir e menguar lo que [por] nos bien visto sera de cada anno, segunt viermos que cunple al biem comunal segunt las disposiçiones de los tienpos que rreclesçieren» ${ }^{85}$.

\section{CONSERVACIÓN DE LAS ORDENANZAS}

La obligación de conservar las ordenanzas era propia y específica del escribano del concejo, al igual que corrían a su cargo la guardia y custodia de los fueros y privilegios de la ciudad.

En el caso de Ourense tan sólo se conserva una ordenanza que hace referencia a este tema. En ella se indica como el escribano del concejo era el encargado de la guardia y custodia de estos documentos, los cuales guardaba en su propia casa. Tras su fallecimiento, su viuda debe hacer entrega de los documentos que éste tenía bajo su custodia a su sucesor: «logo reçeberon da dita Eynes Peres seys cartas escriptas en purgamedeo de coyro seeladas de seellos pendentes de plumo pendurados por syrgo e outras seys cartas escriptas en purgameo de coyro signadas de notarios publicos» ${ }^{86}$. Poco tiempo después se promulga la ordenanza en la que se establecen las nuevas condiciones que van a garantizar la conservación de todos estos documentos: «ordenaron logo que o dito Loys Gonçales que as posese en huna arqua en sua casa et que esta arqua que touese tres pechaduras et que huna das chaues que a teuese o procurador da çibade et outra chaue o dito Loys Gonçales e outra chaue Aluaro Afonso da Fonteyna, rejedores» ${ }^{87}$. A partir de entonces todas las escrituras debían de ser guardadas en este arca, que estaría depositada en la casa

${ }^{85}$ A.H.P.OU. Concellos, C-525/1. 1388. Ordenamiento para la construcción del muro y cerca de la ciudad.

${ }^{86}$ A.H.P.OU. Concellos, Libro I, 191.

${ }^{87}$ A.H.P.OU. Concellos, Libro I, 191. 
del escribano del concejo, y que, para garantizar su seguridad, tenía tres cerraduras cuyas llaves estaban en manos distintas.

A modo de conclusión sólo resta señalar que estas ordenanzas constituyen un testimonio vivo del pasado, a través del cual es posible conocer el entorno social y económico de la vida de la ciudad de Ourense en la Baja Edad Media.

\section{BIBLIOGRAFÍA}

ARTOLA, Miguel, Enciclopedia de la Historia de España, Madrid 1988-1993.

BAREIA, Roque, Primer diccionario general etimológico de la Lengua Española, Madrid 1881.

CORRAL GARCÍA, Esteban, Ordenanzas de los concejos castellanos: formación, contenido y manifestaciones (siglos XIII-XVIII), Burgos 1988.

DURANY CASTRILlO, Mercedes, «Ourense na Idade Media». En Historia de Ourense. A Coruña, 1996.

FALCÓN PÉREZ, M. ${ }^{\text {a }}$ Isabel, «Las actas municipales medievales como fuentes de investigación» Jornadas sobre metodología científica sobre fuentes aragonesas III. Albarracín 1987. Metodología de la investigación científica sobre fuentes aragonesas, Actas de las III jornadas, Zaragoza 1988, 279-365.

FERNÁNDEZ ALONSO, Benito, «Ordenanzas municipales» Boletín de la Comisión Provincial de Monumentos Históricos y Artísticos de Orense, VI, Orense 1928, 189-191.

FERRO COUSELO, Xesús, A vida e a fala dos devanceiros: escolma de documentos en galego dos séculos XIII ao XVI, Vigo 1996.

FRANCO SILVA, Alfonso, Estudios sobre ordenanzas municipales (Siglos XIV-XVI), Cádiz 1998.

GALLEGO DOMÍNGUEZ, Olga, «El Archivo del Concejo de la ciudad de Orense y sus fondos hasta el año 1600», La ciudad hispánica durante los siglos XIII al XVI, I, Madrid 1986, 183-206.

- «Las casas consistoriales de la ciudad de Orense» Boletín Auriense, 10, Orense 1980, 107-117

LADERO QUESADA, Manuel, F., Las ciudades de la Corona de Castilla en la Baja Edad Media (siglos XIII al XV), Madrid [s.a.].

LADERO QUESADA, Miguel Ángel, «Ordenanzas municipales y regulación de la actividad económica en Andalucia y Canarias, siglos XIV-XVII» II Coloquio de Historia Canaria, Canarias 1977.

LÓPEZ CARREIRA, Anselmo, A cidade medieval galega, Vigo 1999.

- A cidade de Ourense no século XV: sociedade urbana na Galicia baixomedieval, Ourense 1998.

- «Conxuntura económica e cambio social no Ourense do século XV» VIII Xornadas de Historia de Galicia, Ourense 1995, 103-132.

- Ourense no século XV: economía e sociedad na Baixa Idade Media, Ourense 1991. 
LUCAS ÁLVAREZ, Manuel, «Para unas normas complementarias de transcripción de documentos en gallego» Cuadernos de Estudios Gallegos, IV, Santiago de Compostela (1949, 95-110.

MARTÍNEZ SUEIRO, Manuel, «Fueros municipales de Orense» Boletín de la Comisión Provincial de Monumentos Históricos y Artísticos de Orense, IV, Orense 1910, 1-94; 1912, 105-135; 1912, 153-162.

ORDENANZAS de la ciudad de Valladolid 1549-1818. Ed. Facs., Valladolid 1988.

PORRAS ARBOLEDAS, Pedro A., «Las ordenanzas municipales: algunas propuestas para su estudio y un ejemplo» Espacio, Tiempo y Forma, Serie III, Historia Medieval, VII, Madrid 1994, 49-64. 